\title{
Variation in platelet count with gestational age, weight and sex in hospitalized newborns
}

\author{
Rabindran $^{1}$, Hemant Parakh ${ }^{2}$, Ramesh J K ${ }^{3}$, Prashant Reddy ${ }^{4}$ \\ ${ }^{1}$ Dr.Rabindran, Consultant Neonatologist, ${ }^{2}$ Dr.Hemant Parakh, Consultant Neonatologist, 3Dr.Ramesh J K, Consultant \\ Pediatrician, 4Dr.Prashant Reddy, Consultant Pediatrician, Sunrise Superspeciality Children's Hospital, Hyderabad.
}

Address for Correspondence: Dr Rabindran, E mail: rabindranindia@ yahoo.co.in

\begin{abstract}
Introduction: Platelet count \& CRP are diagnostic markers of neonatal sepsis. Though the platelet count remains the same throughout the neonatal period, variations in platelet count have been noted based on gestational age, weight $\&$ sex of neonates. Beside other hematological findings, changes in platelet count induced by neonatal sepsis have been the focus of many studies. Objective: To analyze the variation in platelet count with gestational age, weight and sex in hospitalized newborns. Methods: This is a retrospective case analysis of 533 neonates between January-2012 to December-2014. The parameters examined were Baseline Platelet Count, Change In Platelet Count, (Baseline Platelet Count- Change In Platelet Count)/ Baseline Platelet Count, Platelet Nadir, Incidence, Duration \& Severity of Thrombocytopenia. Statistical Analysis: All data were collected in validated preformatted proforma sheet \& analysed sing appropriate statistical methods. Results: 533 babies were studied. About 21.2\% had Culture negative sepsis, 9.75\% had culture positive sepsis \& $69.04 \%$ had no sepsis. No difference in any platelet parameter was noted between female \& male babies. The prevalence of early onset sepsis in our study was $17.44 \%$ \& late onset sepsis was $13.50 \%$. Significant variations of all platelet indices were noted among lower gestational age babies. Significant variations in the Incidence, Prevalence \& duration of thrombocytopenia were noted depending on the weight of the baby. Conclusion: The baseline platelet count of the neonates remains uniform irrespective of sex, weight or gestational age. There are quantitative differences in the platelet response based on weight and gestational age
\end{abstract}

Keywords: Platelet Count, Gestation, Weight, Sex

\section{Introduction}

Platelet count \& CRP are diagnostic markers of neonatal sepsis [1,2]. Though the platelet count remains the same throughout the neonatal period, variations in platelet count have been noted based on gestational age, weight \& sex of neonates. Neonatal Sepsis is infection with or without accompanying bacteremia [3]. It is most common in the smallest and most premature infants $[4,5,6]$.

\section{Objectives}

To analyse the variation in platelet count with gestational age, weight and sex in hospitalized newborns. Manuscript received: 15th Apr 2015 Reviewed: 26th Apr 2015 Author Corrected; 29th Apr 2015 Accepted for Publication: 17th May 2015

Manuscript received: $15_{\text {th }}$ Apr 2015

Reviewed: 26th Apr 2015

Author Corrected; 29th Apr 2015

Accepted for Publication: 17th May 2015

\section{Methodology}

This is a retrospective case analysis between January2012 to December-2014. Name, date of admission, age, platelet count, CRP levels, blood culture reports of 533 neonates during the study period were collected. The data was analysed for variation in platelet count with respect to gestational age and sex.

Unit Protocol for Investigation of Neonatal Sepsis: Direct counting of platelets in an improved Neubauer's Chamber was done \& counts less than 1.5 Lakh / cumm was considered abnormal. CRP in serum was estimated by CRP TurbiLatex Kit using Latex turbimetry \& value more than $6 \mathrm{mg} / \mathrm{L}$ was considered positive. Blood was collected for blood culture in BD BACTEC bottles \& cultured in Sabouraud's Dextrose agar \& Brain Heart Infusion Broth and colony growth was observed. The 
platelet count \& CRP used for this study was the one obtained at the same time as the positive blood culture or the one closest to the time the blood culture was drawn in cases of neonatal sepsis and the admission values in those babies with no sepsis.

Interventions: Management of neonatal sepsis as per standard unit protocol. The study was approved by the Hospital Research and Ethics Committee.

Definition of Parameters: The parameters that were examined in this study were

Baseline Platelet Count: Platelet count obtained at least 24 hours before the time that the blood culture was obtained in cases of neonatal sepsis or the admission values in those babies with no sepsis.

Change In Platelet Count: Platelet count at the time of onset of sepsis in cases of neonatal sepsis or the second $\mathrm{CBC}$ values in those babies with no sepsis.

Platelet Nadir: Lowest platelet count obtained during a 20-day period starting from the time the initial blood culture was drawn in cases of neonatal sepsis or during a 20-day period since admission in those babies with no sepsis.

Incidence of Thrombocytopenia: Number of episodes with a platelet nadir of less than $1,50,000 / \mathrm{mm} 3$ during a 20-day period starting from the time the initial blood culture was drawn in cases of neonatal sepsis or during a 20-day period since admission in those babies with no sepsis.

Duration of Thrombocytopenia: Number of continuous days that the platelet count remained less than $1,50,000 / \mathrm{mm} 3$. If the neonate had no Thrombocytopenia at the time of sepsis, the duration was considered to be zero.

\section{Severity of Thrombocytopenia: [7]}

No Thrombocytopenia -

Platelet count

more than $1,50,000 / \mathrm{mm} 3$

Mild Thrombocytopenia - Platelet count

between $1,00,000$ to $1,50,000 / \mathrm{mm} 3$

Moderate Thrombocytopenia - Platelet count

between 50,000 to $1,00,000 / \mathrm{mm} 3$

Severe Thrombocytopenia - $\quad$ Platelet count less

than $50,000 / \mathrm{mm} 3$

Culture Negative Sepsis was defined as those with clinical signs and symptoms of sepsis, without growth of any pathogen from blood, but with presence of CRP $>6 \mathrm{mg} / \mathrm{L}[8]$.

Statistical Analysis: Chi-square analysis with Yates correction was used for categorical variables \& Student't' test to compare the means. A p-value of < 0.05 was considered significant. Analysis of variance was used to compare groups, and data are expressed as mean \pm standard deviation. Scheffe test was used for pairwise comparisons. Software Statistical Package for Social Sciences was used.

\section{Results}

Among 533 babies who were studied, 21.2\% had Culture negative sepsis, 9.75\% had culture positive sepsis \& $69.04 \%$ had no sepsis. Among culture negative sepsis, 71 babies (62.83\%) were male \& $42(37.16 \%)$ were female ; Among culture positive sepsis, 34 babies (65.38\%) were male \& 18 (34.61\%) were female; Among babies with no sepsis, 216 babies $(58.69 \%)$ were male \& $152(41.3 \%)$ were female (Chi square $\mathrm{p}=0.5332$, not significant).

Among 165 babies with sepsis, 105 babies (63.63\%) were male \& 60 babies were female (36.36\%). Analysing Prevalence of thrombocytopenia among the male and female, 72 babies (22.42\%) among 321 male babies had thrombocytopenia, 60 babies (28.30\%) among 212 female babies had thrombocytopenia, (Chi square $\mathrm{p}<0.1514$, not significant). 
Table 1: Platelet Variations among Male and Female Neonates

\begin{tabular}{|c|c|c|c|c|c|c|}
\hline FACTOR & Levene's p & ANOVA $p$ & $\begin{array}{l}\text { FEMALE } \\
\text { MEAN }\end{array}$ & $\begin{array}{c}\text { FEMALE } \\
\text { SD }\end{array}$ & $\begin{array}{l}\text { MALE } \\
\text { MEAN }\end{array}$ & $\begin{array}{c}\text { MALE } \\
\text { SD }\end{array}$ \\
\hline BASELINE & $p=0.365$ & $p=0.363$ & 2.2719 & 0.8495 & 2.3359 & 0.7561 \\
\hline OUNT CHANGE & $p=0.975$ & $p=0.824$ & 1.874 & 0.9148 & 1.8495 & 0.9168 \\
\hline NADIR & $p=0.859$ & $p=0.445$ & 1.9679 & 0.9415 & 2.0297 & 0.8955 \\
\hline SEVERITY & $p=0.672$ & $p=0.859$ & 0.4623 & 0.8338 & 0.4486 & 0.8934 \\
\hline INCIDENCE & $p=0.585$ & $p=0.561$ & 0.6745 & 1.357 & 0.6044 & 1.3656 \\
\hline DURATION & $p=0.500$ & $p=0.549$ & 1.3585 & 2.7128 & 1.215 & 2.6985 \\
\hline
\end{tabular}

Analysis of variance was used to compare the groups, and data was expressed as mean \pm standard deviation. No difference in any platelet parameter was noted between female \& male babies. The mean Baseline platelet count was a little higher among male babies. The response to sepsis in the form of drop in platelet count was a little more in male babies, however platelet nadir was noted to be low in female babies who already had a lower baseline platelet counts. Female babies had a little higher incidence of thrombocytopenia with prolonged duration. However none of the differences in platelet parameters between male \& female babies reached statistical significance

Table 2: Platelet Variations among different gestational age groups

\begin{tabular}{|c|c|c|c|c|c|c|c|c|c|c|c|c|c|}
\hline $\begin{array}{r}\text { GA } \\
\text { WK }\end{array}$ & $\mathrm{n}$ & $\begin{array}{l}\text { BASELINE } \\
\text { MEAN }\end{array}$ & $\begin{array}{c}\text { BASELINE } \\
\text { SD }\end{array}$ & $\begin{array}{c}\text { CHANGE } \\
\text { MEAN }\end{array}$ & $\begin{array}{c}\text { CHANGE } \\
\text { SD }\end{array}$ & $\begin{array}{l}\text { NADIR } \\
\text { MEAN }\end{array}$ & $\begin{array}{c}\text { NADIR } \\
\text { SD }\end{array}$ & $\begin{array}{c}\text { SEVERITY } \\
\text { MEAN }\end{array}$ & $\begin{array}{c}\text { SEVERITY } \\
\text { SD }\end{array}$ & $\begin{array}{c}\text { INCI } \\
\text { MEAN }\end{array}$ & $\begin{array}{c}\text { INCI } \\
\text { SD }\end{array}$ & $\begin{array}{c}\text { DURATION } \\
\text { MEAN }\end{array}$ & $\begin{array}{l}\text { DURATION } \\
\text { SD }\end{array}$ \\
\hline 28 & 10 & 2.281 & 0.5925 & 1.7744 & 1.2587 & 1.188 & 0.657 & 1.3 & 1.0593 & 2.1 & 1.912 & 4.9 & 4.1218 \\
\hline 29 & 1 & 1.77 & $?$ & , & , & 1.77 & $?$ & 0 & $?$ & 0 & $?$ & 0 & $?$ \\
\hline 30 & 12 & 2.0858 & 0.3837 & 1.1555 & 0.609 & 0.9942 & 0.755 & 1.75 & 1.2154 & 2.75 & 2.4541 & 5.5833 & 4.6015 \\
\hline 31 & 6 & 2.11 & 0.8515 & 1.4467 & 1.049 & 1.2183 & 0.993 & 1.5 & 1.3784 & 2.5 & 2.1679 & 5.3333 & 4. 6762 \\
\hline 32 & 21 & 2.0243 & 0.6545 & 1.4425 & 0.6132 & 1.5271 & 0.777 & 0.7619 & 0.9437 & 1.0952 & 1.3381 & 2.4286 & 3.295 \\
\hline 33 & 17 & 2.1041 & 0.4684 & 2.054 & 0.9611 & 1.8276 & 0.739 & 0.5294 & 0.9432 & 0.6471 & 1.2217 & 1.1765 & 2.3515 \\
\hline 34 & 34 & 2.2465 & 0.6084 & 1.9535 & 0.8321 & 1.96 & 0.728 & 0.3529 & 0.6912 & 0.4706 & 0.9288 & 0.9706 & 2.0373 \\
\hline 35 & 33 & 2.4252 & 0.6372 & 2.3123 & 0.7748 & 2.1888 & 0.665 & 0.2424 & 0.6629 & 0.4242 & 1.2755 & 0.8182 & 2.4932 \\
\hline 36 & 87 & 2.2349 & 0.7624 & 1.7736 & 0.785 & 1.9797 & 0.842 & 0.4598 & 0.8734 & 0.5057 & 1.077 & 1.0805 & 2.3189 \\
\hline 37 & 201 & 2.4304 & 0.9396 & 1.859 & 0.9815 & 2.1405 & 1.045 & 0.408 & 0.8618 & 0.5871 & 1.4435 & 1.1343 & 2.6376 \\
\hline 38 & 65 & 2.3691 & 0.6947 & 2.2114 & 1.0281 & 2.1712 & 0.743 & 0.2154 & 0.5726 & 0.3077 & 0.9001 & 0.6 & 1.8439 \\
\hline 39 & 25 & 2.1964 & 0.8019 & 1.8527 & 0.8183 & 2.0336 & 0.849 & 0.44 & 0.8699 & 0.52 & 1.0847 & 0.92 & 2.0191 \\
\hline 40 & 21 & 2.031 & 0.6096 & 1.5033 & 0.458 & 1.8762 & 0.692 & 0.3333 & 0.6583 & 0.4286 & 0.8106 & 0.7143 & 1.4193 \\
\hline
\end{tabular}

Analysis of variance was used to compare the groups, and data was expressed as mean \pm standard deviation. Chi Square was used to compare categorical variables. We observed that the Baseline platelet count was comparable among all gestational groups. However the severity of thrombocytopenia \& incidence of thrombocytopenia was more among babies with lower gestational age as compared to more mature babies. Likewise the duration of thrombocytopenia was prolonged in babies with lower gestation as compared to more mature babies.

Table 3: Platelet Variations Gestation Wise- Statistical Analysis

\begin{tabular}{|l|c|c|c|}
\hline PARAMETER & LEVENE P & ANOVA P & CHI SQUARE P \\
\hline BASELINE PLATELET COUNT & 0.02 & 0.217 & \\
\hline CHANGE IN PLATELET COUNT & 0.06 & 0.013 & \\
\hline PLATELET NADIR & 0.229 & $<0.001$ & \\
\hline INCIDENCE OF THROMBOCYTOPENIA & $<0.001$ & $<0.001$ & \\
\hline DURATION OF THROMBOCYTOPENIA & $<0.001$ & $<0.001$ & \\
\hline PREVALENCE OF THROMBOCYTOPENIA & & & $<0.0001$ \\
\hline TYPE OF SEPSIS (EARLY/ LATE) & & & 0.0001 \\
\hline
\end{tabular}


We analyzed the platelet variations based on gestation using Anova \& chi square. There was no statistical difference in the baseline platelet count among the babies with different gestaional age. However we noted a significant difference in all the other platelet parameters (change in count, nadir, incidence, prevalence \& duration of thrombocytopenia) when we analysed the multiple gestational groups using anova. Significant variations of all platelet indices were noted among lower gestational age babies.

Table 4: Gestaional age wise prevalence of thrombocytopenia \& type of sepsis

\begin{tabular}{|c|c|c|c|c|c|c|c|}
\hline $\begin{array}{r}\text { GA } \\
\text { WK }\end{array}$ & $\begin{array}{l}\text { No } \\
\text { TEP }\end{array}$ & TCP & & $\begin{array}{l}\text { EARLY } \\
\text { ONSET }\end{array}$ & $\begin{array}{c}\text { LATE } \\
\text { ONSET }\end{array}$ & $\begin{array}{c}\text { No } \\
\text { SEPSIS }\end{array}$ & \\
\hline 28 & 3 & 7 & $10(1.9 \%)$ & 2 & 6 & 2 & $10(1.9 \%)$ \\
\hline 29 & 1 & $\mathbf{0}$ & $1(0.2 \%)$ & $\mathbf{0}$ & 1 & $\mathbf{0}$ & $1(0.2 \%)$ \\
\hline 30 & 3 & $\mathbf{9}$ & $12(2.3 \%)$ & 4 & 5 & 3 & $12(2.3 \%)$ \\
\hline 31 & 2 & 4 & $6(1.1 \%)$ & $\mathbf{0}$ & 3 & $\mathbf{3}$ & $6(1.1 \%)$ \\
\hline 32 & 11 & 10 & $21(3.9 \%)$ & 2 & 2 & 17 & $21(3.9 \%)$ \\
\hline 33 & 12 & 5 & $17(3.2 \%)$ & 2 & 2 & 13 & $17(3.2 \%)$ \\
\hline 34 & 26 & 8 & $34(6.4 \%)$ & 7 & 2 & 25 & $34(6.4 \%)$ \\
\hline 35 & 29 & 4 & $33(6.2 \%)$ & 5 & 2 & 26 & $33(6.2 \%)$ \\
\hline 36 & 67 & 20 & $87(16.3 \%)$ & 12 & 7 & 68 & $87(16.3 \%)$ \\
\hline 37 & 155 & 46 & $201(37.7 \%)$ & 41 & 27 & 133 & $201(37.7 \%)$ \\
\hline 38 & 55 & 10 & $65(12.2 \%)$ & 7 & $\mathbf{9}$ & 49 & $65(12.2 \%)$ \\
\hline 39 & 21 & 4 & $25(4.7 \%)$ & 6 & 3 & 16 & $25(4.7 \%)$ \\
\hline 40 & 16 & 5 & $21(3.9 \%)$ & 5 & $\mathbf{3}$ & 13 & $21(3.9 \%)$ \\
\hline
\end{tabular}

Among the 533 babies in the study group majority (nearly 50\%) were near term (35-37 weeks). The prevalence of thrombocytopenia was noted to be more in babies less than 32 weeks. Beyond 34 weeks early onset sepsis onset was more common than late onset sepsis, however in babies less than 32 weeks, late onset sepsis was more common than early onset sepsis.

Table 5: Platelet Variations Weight Wise- Statistical Analysis

\begin{tabular}{|l|c|c|}
\hline PARAMETER & LEVENE P & ANOVA P \\
\hline BASELINE PLATELET COUNT & 0.063 & 0.736 \\
\hline CHANGE IN PLATELET COUNT & $<0.001$ & 0.583 \\
\hline PLATELET NADIR & 0.041 & 0.065 \\
\hline INCIDENCE OF THROMBOCYTOPENIA & $<0.001$ & 0.003 \\
\hline DURATION OF THROMBOCYTOPENIA & $<0.001$ & $<0.001$ \\
\hline PREVALENCE OF THROMBOCYTOPENIA & $<0.001$ & $<0.001$ \\
\hline TYPE OF SEPSIS (EARLY/ LATE) & $<0.001$ & 0.324 \\
\hline
\end{tabular}

We analysed the platelet variations based on weight using Anova \& chi square. There was no significant difference in the baseline platelet count, change in count and platelet nadir or the occurrence of early/ late onset sepsis based on the weight among the neonates. However statistical significant difference was noted in the incidence, duration \& prevalence of thrombocytopenia based on the weight of the newborns. Babies with lower weight had more incidence \& prevalence of thrombocytopenia. Neonates with lower weight had more prolonged thrombocytopenia. There are quantitative differences in the platelet response based on weight and gestational age

\section{Discussion}

Platelet variations among male and female neonates: In our study the, among 165 babies with sepsis, 105 babies $(63.63 \%)$ were male \& 60 babies were female $(36.36 \%)$. Several other workers have reported similar finding. Khalessi N et al [9], Muhammad Ali Sheikh et al [10], Chandra A et al [11], Antoniette BWM et al[12], Schuchat A et al[13] \& Kuruvilla KA et al [14] noted that the incidence of neonatal sepsis was higher in 
male than female neonates. This is probably due to the fact that the factors regulating the synthesis of gamma globulin are situated on the $\mathrm{X}$ - chromosome and male has only one $\mathrm{X}$-chromosome [11]. In Indian scenario we think high male:female birth ratio and neglected female neonates add to high rate of neonatal sepsis in male child. The male: female ratio was 1.36: 1 in a study by Ramesh Bhat Y et al [15].

In our study the mean incidence of Thrombocytopenia among neonatal sepsis was $0.6745 \pm 1.357$ in female \& $0.6044 \pm 1.3656$ in male babies. (Anova $\mathrm{p}$ was 0.561 ; not significant).Anil K Gupta et al [16] also observed that sex does not predict the thrombocytopenia among NICU neonates.

Platelet Variations among Different Gestational Age: In our study, there was significant variations of platelet count based on the gestational age. Significant Change in platelet count $\{$ anova $\mathrm{P}=0.013\}$, platelet Nadir $\{$ anova $\mathrm{P}<0.001\}$, severity of thrombocytopenia \{anova $\mathrm{P}<0.001\}$, Incidence of thrombocytopenia \{anova $\mathrm{P}<0.001\}$, duration of thrombocytopenia \{anova $\mathrm{P}<0.001$ \}, prevalence of Thrombocytopenia $\{$ Chi Square $\mathrm{p}<0.0001\}$, the type of sepsis (early onset or late onset sepsis) \{Chi Square $\mathrm{p}=0.0001\}$ were noted. Ramesh Bhat $Y$ et al [15], Hussein AB et al[17], \& Karen M.Puopolo et al [18] observed that the incidence of septicemia was higher in preterm neonates. Chakravorty $\mathrm{S}$ et al[19] noted that Thrombocytopenia occurs in up to a third of preterm neonates.

However Abdalla Alshorman et al[20] \& Anil K Gupta et al[16] observed that gestational age does not predict the thrombocytopenia among NICU neonates. Roberts I et al [21,22,23], Aman I et al [24], Van den Hof MC et al [25] \& Sainio S et al[26] noted that the prevalence of thrombocytopenia is much higher among preterm and low birth weight neonates.

Platelet variations among different weight babies: In our study, there were significant variations of platelet count based on the weight. Significant variations in the Incidence of thrombocytopenia \{anova $\mathrm{P}=0.003$, duration of thrombocytopenia $\{$ anova $\mathrm{P}<0.001$ \} and prevalence of Thrombocytopenia $\{$ anova $\mathrm{P}<0.001\}$ were noted depending on the weight of the baby.

Betty C et al [27] \& Soman et al [28] observed that septicemia was more common in low birth weight and preterm babies. Higher incidence of sepsis in low birth weight is because of the low maternal acquired $\mathrm{IgG}$ and inherent susceptibility to infection.

Placental transport of IgG from maternal to fetal circulation increases with maturity, \& this transport is hampered in Low birth weight babies neonates who are often the products of placental insufficiency [29].

Anil K Gupta et al [16] stated that LBW babies showed statistically significant (P 0.009) thrombocytopenia due to their limited ability to compensate for accelerated destruction of platelets.

\section{Summary}

No difference in any platelet parameter was noted between female $\&$ male babies. There was a statistically significant difference in all the platelet parameters except baseline platelet count among the gestational subgroups. Statistical significant difference was noted in the incidence, duration \& prevalence of thrombocytopenia based on the weight of the newborns.

\section{Conclusion}

The baseline platelet count of the newborns remains uniform irrespective of sex, weight or gestational age. There are quantitative differences in the platelet response based on weight and gestational age which may help in prompt diagnosis and management of the newborns.

Funding: Nil

Conflict of interest: Nil

Permission from IRB: Yes

\section{References}

1. Modanlou HD, Ortiz OB. Thrombocytopenia in neonatal infection. Clin Pediatr (Phila). 1981 Jun;20(6):402-7.

2. Storm W. Use of thrombocytopenia for the early identification of sepsis in critically ill newborns. Acta Paediatr, Acad Sci Hung. 1982(23):349-355.

3. Shankar MJ, Agarwal R, Deorari AK. Sepsis in the new born. Indian J Pediatr; 2008 Mar;75(3):261-6

4. Moro ML, De Toni A, Stolfi I, Carrieri MP, Braga M, Zunin C. Risk factors for nosocomial sepsis in newborn intensive and intermediate care units. Eur J Pediatr. 1996 Apr;155(4):315-22. 
5. Khadilkar V, Tudehope D, Fraser S. A prospective study of nosocomial infection in a neonatal intensive care unit. J Paediatr Child Health. 1995 Oct, 31(5):387391

6. Escobar GJ. The neonatal "sepsis work-up" personal reflections on the development of an evidence-based approach toward newborn infections in a managed care organization. Pediatrics. 1999 Jan;103(1 Suppl E):360373.

7. Zaccheaus A Jeremiah, Justina E Oburu. Pattern and prevalence of neonatal thrombocytopenia in Port Harcourt, Nigeria;Pathol Lab Med Int. 2010:(2) 27-31

8. Marzban A1, Samaee H, Mosavinasab N. Changing trend of empirical antibiotic regimen: experience of two studies at different periods in a neonatal intensive care unit in Tehran, Iran. Acta Med Iran. 2010 Sep-Oct; 48(5):312-5.

9. Sanii S, Khalessi N, Khosravi N, Zareh Mehrjerdi F.The Prevalence and Risk Factors for Neonatal Thrombocytopenia among Newborns Admitted to Intensive Care Unit of Aliasghar Children's Hospital. IJBC. 2013; 5 (2) :41-45.

10. Sidra Younis, Muhammad Ali Sheikh, Amjad Ali Raza.Diagnostic Accuracy of C-Reactive Protein in Neonatal Sepsis; J. Bioresource Manage. 2014; 1(1): 33-42.

11. Chandra A, Rao MN, Srinivas M and Shyamala S (1988). Rapid diagnostic tests in neonatal septicemia.Indian J Pediatr 1988;55(6); 947-953.

12. Antoniette BWM and Flora DIP (2005). Clinical correlation of neonatal and maternal haematological parameters as predictors of neonatal sepsis. Pediatric Infect Dis Society Of Philippines J;9(2)36-43.

13. Schuchat A, Zywicki SS, Dinsmoor MJ, Mercer B, Romaguera J, O'Sullivan MJ. Risk factors and opportunities for the prevention of early - onset neonatal sepsis: a multicenter case-control study. Paediatrics 2000; 105: 21-26.

14. Kuruvilla KA, Pillai S, Jesudasan M, Jana AK. The bacterial profile of sepsis in a neonatal unit in south India. Indian Paediatr 1998; 35:851-58.

15. Ramesh Bhat Y, Lincy P. Early Onset of Neonatal Sepsis: Analysis of the Risk Factors and the Bacterial
Isolates by Using the BacT Alert System; J Clin Diagn Res. 2011-November(Suppl-2),Vol-5(7):1385-1388

16. Anil K Gupta, Sudarshan Kumari, Abhishek Singhal , Aruna Bahl ; Neonatal thrombocytopenia and platelets transfusion; Asian J Transfus Sci. 2012, July-Dec; 6(2): 2012: 161-164

17. Hussein $A B$, Khaled MAR. CRP in neonate with suspected septicemia; Rawal Medical J;(20070;32(1)2427.

18. Karen M. Puopolo. In: Manual of Neonatal Care, 5th ed. Cloherty JP, Stark AR (Eds.), LippincottWilkins, Philadelphia, 2004; 287-313.

19. Chakravorty S, Murray N, Roberts I. Neonatal thrombocytopenia. Early Hum Dev. 2005; Jan;81(1):3541

20. Abdalla Alshorman. The Effect of Neonatal Sepsis on Platelet Count and their Indices et al. $83 \mathrm{~J}$ Med J 2008; June: Vol. 42(2) http///dar.ju.edu.jo/jmj. 83.

21. Roberts I, Murray NA. Neonatal thrombocytopenia.Semin Fetal Neonatal Med. 2008 Aug; 13(4):256-64

22. Roberts I, Stanworth S, Murray NA.Thrombocytopenia in the neonate. Blood Rev. 2008 Jul;22(4):173-86. doi: 10.1016/j.blre.2008.03.004.

23. Roberts IA, Murray NA. Neonatal thrombocytopenia: new insights into pathogenesis and implications for clinical management. Curr Opin Pediatr. 2001;13:16-21.

24. Aman I, Hassan KA, Ahmad TM. The study of thrombocytopenia in sick neonates. J Coll Physicians Surg Pak; 2004 May; 14(5):282-5

25. Van den Hoogen A, Gerards LJ, Verboon-Maciolek MA. Long-term trends in the epidemiology of neonatal sepsis and antibiotic susceptibility of causative agents. Neonatology. 2010;97(1):22-8. doi: 10.1159/000226604

26. Sainio S, Jarvenpaa A S, Renlund M.Thrombocytopenia in term infants: a populationbased study. Obstet Gynecol 2000 Mar;95(3):441- 446.

27. Betty C, Sohi I. Early onset neonatal sepsis. Indian J Paediatr 2005;72(1) :23-26. 
28. Soman M, Green B, Daling J. Risk factors for early neonatal sepsis. Am J Epidemiol 1985 May;121(5): 712-9
29. Bhakoo ON and Singh M. Perinatal risk factors in neonatal bacterial sepsis. Indian J Pediatr 1988;55(6) 941-946.

\section{How to cite this article?}

Rabindran, Hemant Parakh, Ramesh J K, Prashant Reddy.Variation in platelet count with gestational age, weight and sex in hospitalized newborns . Pediatr Rev: Int J Pediatr Res 2015;2(1):1-7.doi:10.17511/ijpr.2015.i01.01 